\title{
Identification of Bioactive Compounds of the Endophytic Fungus Aspergillus egypticus-HT166S Inhibiting the Activity of Pancreatic $\alpha$-Amylase
}

\author{
(D) Dilorom RUZIEVA*, (D) Tashkan GULYAMOVA, (D) Saodat NASMETOVA, (D) Iqbol MUKHAMMEDOV, (D) Gulchehra RASULOVA \\ Institute of Microbiology of the Academy of Sciences, Tashkent, Uzbekistan
}

\begin{abstract}
Objectives: Diabetes mellitus (DM) is a worldwide increasing problem, associated with development of hyperlipidemia, coronary heart disease, hypertension, and other chronic diseases. Decreasing of glucose absorption by inhibition of $\alpha$-amylase is one of the therapeutic approaches to retard diabetes type 2. Pancreatic $\alpha$-amylase (PA) inhibition widely studied mechanism for determination of potential of natural compounds as antidiabetic agents. The aim of this work was identification of inhibitory secondary metabolites produced by Aspergillus egypticus, isolated from Helianthus tuberosus.

Materials and Methods: The PA inhibitory activity of the secondary metabolites determined using iodometric method. Isolation of inhibitory compounds was carried out by column chromatography, thin layer chromatography and liquid chromatography-tandem mass spectrometry (LCMS/MS) analysis.

Results: It was found that the inhibitory concentration of a compound, $\mathrm{K}-10\left(\mathrm{R}_{\mathrm{f}}: 0.74\right)$, isolated from metanolic extract of $A$. egypticus was 4.82 mg/ $\mathrm{mL}$. LC-MS/MS analysis of K-10 showed polymethoxylated flavones (PMF).

Conclusion: The fungal endophyte A. egypticus-HT166S can be considered a source of PMF as potential agents for developing new PA inhibitors.

Key words: Diabetes mellitus, endophyte, diabetes, secondary metabolites, inhibitory activity, column chromatography, LC-MS/MS
\end{abstract}

\section{INTRODUCTION}

Diabetes mellitus (DM) is a metabolic syndrome characterized by hyperglycemia and abnormalities in the metabolism of carbohydrates, fats, and proteins, leading to insulin secretion or/and sensitivity. The consumption of a high-carbohydrate diet causes postprandial hyperglycemia with the development of a complete symptomatic picture of type $2 \mathrm{DM}^{2}$ The number of patients with diabetes is growing dramatically worldwide. According to World Health Organization forecasts, by 2040, the number of patients with diabetes will be 642 million. Simultaneously, $90 \%$ of the total number of patients are with type 2 DM. $^{3}$

DM therapy is aimed to prevent hyperglycemia and subsequent complications associated with cardiovascular factors, and in general, to improve the quality of life.
One of the treatment approaches of type $2 \mathrm{DM}$ is reducing postprandial blood glucose, caused by delayed glucose absorption by inhibition of polysaccharide breakdown to mono- and disaccharides by $\alpha$-amylase and $\alpha$-glucosidase in the intestine. ${ }^{2,4-7}$ Inhibitors of these enzymes prolong the total carbohydrate digestion time, contributing to a decrease in the rate of glucose absorption, followed by blocking the postprandial increase in glucose levels. ${ }^{8}$ However, most known to date inhibitors (acarbose, miglitol, and voglibose) have severe undesirable side effects; abdominal pain, bloating, diarrhea, kidney cancer, liver damage, and acute hepatitis. 6,9 The development of new natural inhibitors of pancreatic $\alpha$-amylase and $\alpha$-glucosidase that can restore normoglycemia without side effects requires appropriate research in herbal medicine and alternative medicine. 
Some secondary metabolites of the antidiabetic plants successfully demonstrate the properties of inhibitors of carbohydrate degrading enzymes, which may help control type 2 diabetes. $2,4,5,7$ Recently, endophytes of medicinal plants are the most attractive source of natural product sources with high structural diversity and bioactivity and have several advantages over plant raw materials. ${ }^{10}$ The endophytes of diabetic plants are of particular interest since they can probably produce compounds that mediate the antidiabetic properties of the host plants. ${ }^{4-6}$

For example; Colletotrichum capsici isolated from Eugenia cumini L. has strong antibacterial efficacy and antidiabetic action and contains fatty acids and phenolic compounds." Similar results were reported by Govindappa et al..$^{12}$ who in vitro determined the antidiabetic, antioxidant, and anticholinesterase activities of the methanolic extract of the endophyte Cladosporium uredinicola isolated from endemic plant Calophyllum tomentosum Wight. Phytochemical analysis of the fungal extract showed presence of flavonoids, tannins, alkaloids, glycosides, phenols, terpenoids, and coumarins. ${ }^{12}$

In our previous studies of the roots, stems, leaves, and tubers of Helianthus tuberosus L. growing in Uzbekistan, there were obtained 17 endophytic fungal isolates related to different genera. ${ }^{13}$ The most active Aspergillus egypticus-HT166S inhibited $\alpha$-amylase activity for more than $80 \%$. $^{14}$

The fractionation of crude ethylacetate extract of $A$. egypticusHT166S metabolites by the stepwise extraction with polar and non-polar solvents, it was found that the metabolites with the highest inhibitory activity were recovered in the methanol fraction. ${ }^{15}$

In this regard, this work aims to separate and study of inhibitory compounds in the methanol extract of the endophytic fungus $A$. egypticus-HT166S.

\section{MATERIALS AND METHODS}

\section{Cultivation of $A$. egypticus-HT166S endophytes}

The endophytic fungus $A$. egypticus-HT166S, previously isolated from the stem of $H$. tuberosus, was grown submergely in Czapek-Dox medium on an orbital shaker at 160 rpm for 7 days. ${ }^{14}$ The biomass was separated from the culture liquid by centrifugation at $6000 \mathrm{rpm}$.

\section{Fractionation of secondary metabolites}

Fractionation of secondary metabolites of A. egypticus-HT166S biomass was carried out according to the scheme proposed by Kumar et al. ${ }^{5}$, including sequential extraction with water, methanol: hexane (1:1), and butanol. As a result, a methanol extract was obtained with an inhibitory activity of $75.4 \%$. The extract was dried on a rotary evaporator and $1 \mathrm{~mL}$ of dimethyl sulfoxide was added. The resulting dry methanol extract was stored at $4^{\circ} \mathrm{C}$ for reuse..$^{15}$

\section{Column chromatography}

The methanol extract $(500 \mathrm{mg}$ ) was applied to a column ( $2 \mathrm{x}$ $25 \mathrm{~cm}$ ) filled with $20 \mathrm{~g}$ of silica gel (100/250, LaChema) and eluted in chloroform: methanol 50:1 1:1 graduated solvent system to yield fractions at a flow rate of a mobile phase 1.5 $\mathrm{mL} / \mathrm{min}$. Those fractions with the same $R_{f}$ value after thin layer chromatographic analysis were pooled together and evaporated till the dried fraction (A1-M12) was obtained."

\section{Thin layer chromatography}

Samples of $25 \mu \mathrm{L}$ were loaded onto plates (Sigma-Aldrich, Germany) and chromatographed in the chloroform: Methanol (5:1) system. The plates were scanned with ultraviolet light at a wavelength of $254 \mathrm{~nm}$. Samples with the same $R_{f}$ values were pooled and dried.

Liquid chromatography-tandem mass spectrometry (LC-MS) analysis

The mass spectra of the fractions obtained on a Q-TOF LCMS Agilent Technologies 6520V device under the following conditions: ESI positive ion mode, positive ion electrospray method, drying gas flow rate of $5 \mathrm{~L} / \mathrm{min}$, drying gas temperature of $300^{\circ} \mathrm{C}$, ion acceleration voltage on the skimmer $35 \mathrm{~V}$, fragmented $175 \mathrm{~V}$, range MS 150-1000 m/z, target MS-MS 50$1000 \mathrm{~m} / \mathrm{z}$, collision energy - 30, 40, 50, 65. Samples injected onto a Zorbax SB C18 ( $3 \mu \mathrm{m}, 150 \times 0.5 \mathrm{~mm}$ ) column (Agilent Technologies 1200) with a mobile phase: A) $0.1 \%$ formic acid, B) acetonitrile $+0.1 \%$ formic acid. Elution on the Agilent Technologies 1260 Cap pump at $15 \mu \mathrm{L} / \mathrm{min}$ : 5 min 60\%, 15-20 min - 90\%, 25 min - 60\% of the mobile phase B.

\section{Determination of the inhibitory activity}

Each sample obtained after the separation of the methanol fraction on the column was examined for inhibitory activity. The activity of the $\alpha$-amylase fractions was determined according to the method used in plant extracts. ${ }^{16}$ The starch solution prepared as a substrate in an amount of $1 \mathrm{~g} / 10 \mathrm{~mL}$ of water, boiled for $2 \mathrm{~min}$, the sample volume was adjusted to $100 \mathrm{~mL}$ with distilled water. $100 \mathrm{~mL}$ of pancreatic $\alpha$-amylase $(0.1 \mathrm{M}$ Na-acetate buffer is $13 \mathrm{~mL}$ at $\mathrm{pH}$ 7.2), $100 \mu \mathrm{g}$ of endophyte extract, $2 \mathrm{~mL}$ of acetate buffer were incubated for $10 \mathrm{~min}$ at $30^{\circ} \mathrm{C}$ for $2 \mathrm{~mL}$ starch prepared from the preparation. The incubation reaction was then stopped and immersed in $10 \mathrm{~mL}$ of an aqueous reagent, and the optical density was measured at $630 \mathrm{~nm}$ on a SPECOL-1300. To prepare the iodine reagent, $0.5 \mathrm{~g}$ of crystalline iodine, $5 \mathrm{~g}$ of potassium iodide, and 250 $\mathrm{mL}$ of dissolved in water were taken; $2 \mathrm{~mL}$ of this reagent was added to $100 \mathrm{~mL}$ of $0.1 \mathrm{M} \mathrm{HCl}$ to obtain a working solution. The inhibitory activity was expressed by the formula: $\left(A_{0}-A_{t}\right) / A_{0} x$ $100 \%$, where $A_{0}$ is the absorption of the control sample, and $A_{t}$ is the absorption of the experimental sample, respectively. As a comparison drug, acarbose was used from a commercial drug "Glucobay" (Bayer Pharma AG, Germany) was used.

The concentration causing $50 \%$ inhibition of pancreatic $\alpha$-amylase $\left(\mathrm{IC}_{50}\right)$ by the test samples was quantified as described by Murado et al..$^{17}$

\section{Calculation of results}

The values are expressed as the mean value of \pm standard deviation (n: 3). Statistical analysis has not been performed for evaluation of the results. 


\section{RESULTS AND DISCUSSION}

As mentioned above, for the isolation of bioactive substances with high inhibitory activity, the total ethyl acetate extract biomass of $A$. egypticus-HT166S was fractionated in solvents of different polarities and the highest inhibitory activity was extracted by methanol.15

Figure 1 demonstrates the total ion chromatogram of the initial methanol fraction of $A$. egypticus-HT166S. As can be seen from the chromatographic data, the methanol fraction contained many substances, three of which are represented by relatively high peaks.

As can be seen from the data in Table 1, the inhibitory activity of the obtained metabolite samples varies widely from 7.0 to
$76.2 \%$. Simultaneously, the highest level of inhibitory activity was noted in the $\mathrm{K}-10$ fraction with an $\mathrm{R}_{\mathrm{f}}$ value of 0.74 and the content of secondary metabolites constituting $10 \%$ of the initial weight of the dry methanol fraction (Table 1).

Qualitative phytochemical analysis of K-10 fraction showed a positive reaction to flavonoids, as evidenced by the formation of an intense yellow by $20 \% \mathrm{NaOH}$ and disappearance of color by $70 \% \mathrm{HCl}^{18}$

Note that over the past 20 years, scientific attention has been paid to natural compounds, such as flavonoids, which serve as antidiabetic agents. Flavonoids improve the pathogenesis of diabetes and its complications by regulating glucose metabolism, liver enzyme activity, and lipid profile. In vitro and

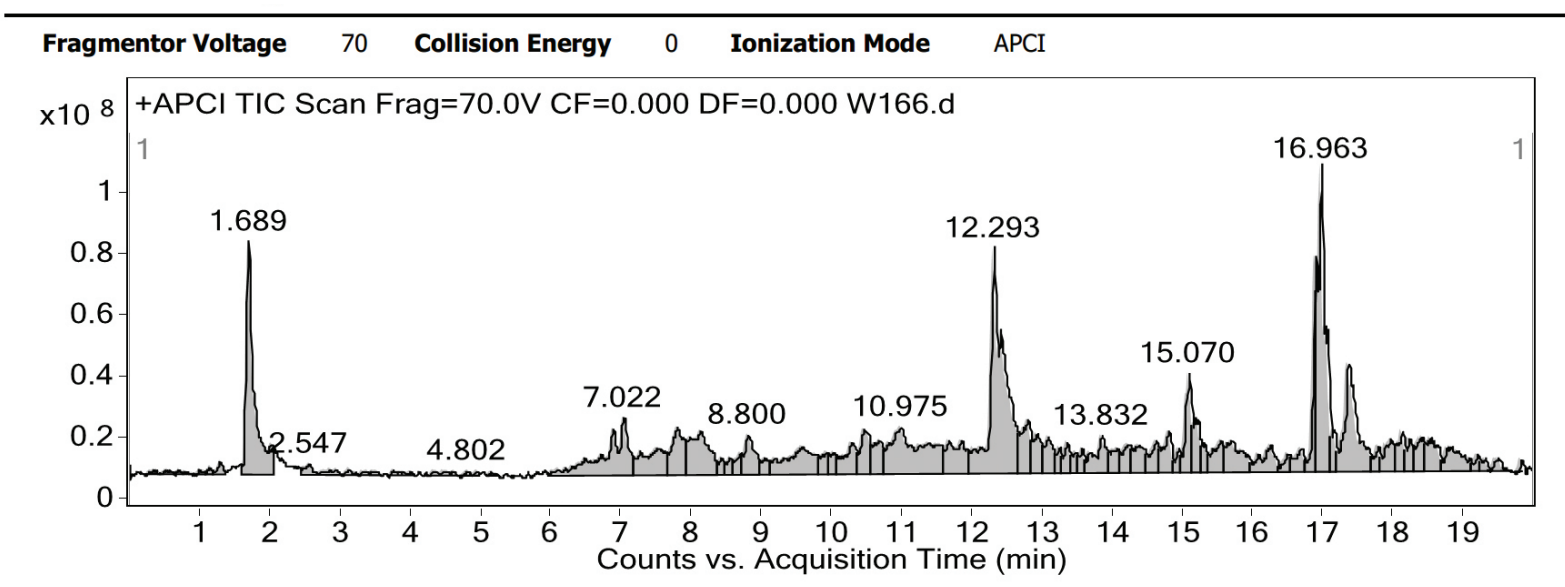

Figure 1. Total ion chromatogram of the total methanol fraction of the biomass Aspergillus egypticus-HT166S.

Because of fractionation of the methanol extract by column chromatography in a gradient concentration of chloroform: methanol 50:1 1:1, twelve fractions (A1-M12) were obtained, which were dried on a rotary evaporator. Each obtained fraction of metabolites was further evaluated by inhibition of pancreatic amylase

Table 1. Content and inhibitory activities of samples obtained from purification on a column of the total methanol fraction of Aspergillus egypticus-HT166S

\begin{tabular}{llll} 
Fractions & $R_{f}$ & Dry weight, $\%$ & $\alpha$-Amylase inhibition, $\%$ \\
\hline A-1 & 0.13 & $3.8 \pm 0.02$ & $14.6 \pm 0.29$ \\
\hline B-2 & 0.22 & $4.5 \pm 0.03$ & $15.2 \pm 0.29$ \\
\hline C-3 & 0.30 & $7.8 \pm 0.37$ & $28.6 \pm 0.30$ \\
\hline D-4 & 0.37 & $4.1 \pm 0.35$ & $17.7 \pm 0.27$ \\
\hline E -5 & 0.44 & $3.2 \pm 0.33$ & $25 \pm 0.28$ \\
\hline F-6 & 0.48 & $2.7 \pm 0.13$ & $15 \pm 0.34$ \\
\hline G-7 & 0.52 & $3.1 \pm 0.04$ & $24.3 \pm 0.29$ \\
\hline H-8 & 0.54 & $6.5 \pm 0.34$ & $7.0 \pm 0.26$ \\
\hline J-9 & 0.6 & $5.2 \pm 0.24$ & $24 \pm 0.30$ \\
\hline K-10 & 0.74 & $10 \pm 0.17$ & $76.2 \pm 0.29$ \\
\hline L-11 & 0.86 & $6.6 \pm 0.14$ & $18.8 \pm 0.30$ \\
\hline M-12 & 0.97 & $2.3 \pm 0.03$ & - \\
\hline Total methanol fraction & - & 100 & $75.4 \pm 0.27$
\end{tabular}

Each value is the average of three analyses \pm standard deviation 
in vivo studies have shown that they can prevent diabetes and its complications. ${ }^{19}$ In identifying flavonoids, we referred to the experimental data of Zhang et al. ${ }^{20}$, who developed a fast and efficient analytical method of tandem mass spectrometry with high performance liquid chromatography for the structural characterization of flavonoids from complex extracts of traditional Chinese medicines.

The mass spectral analysis of the bioactive K-10 sample showed compounds with molecular ions $[\mathrm{M}+\mathrm{H}]^{+}$with $\mathrm{m} / \mathrm{z} 359.0, \mathrm{~m} / \mathrm{z}$ 345.0, and $\mathrm{m} / \mathrm{z} 327.0$ (Figure 2).

On comparative analysis of our results with the literature data, the compounds were assigned as polymethoxylated flavones (PMF).

PMF is a subclass of flavonoids in which all or almost all hydroxyls are blocked by methylation, have high oral bioavailability, exhibit anti-allergic, antioxidant, antibacterial, antiproliferative, anti-inflammatory, and anti-cancer activities. ${ }^{21}$ The literature provides information on PMFs, mainly nobiletin, tangeretin, sinensetin, and isosinensetin from citrus plants, and discusses their antidiabetic effects in vitro. ${ }^{22}$ For example; nobiletin, the polymethoxylated flavonoid, reduces the inflammation associated with gestational DM (GDM), a condition in which pregnant women suffer from carbohydrate intolerance during pregnancy. Nobiletin improved glucose metabolism in animal and human GDM models and may be a novel therapeutic agent for preventing GDM. ${ }^{23}$ Sundaram et al. ${ }^{24}$ evaluated the antihyperglycemic potential of PMF tangeretin on the activity of key enzymes of carbohydrate and glycogenic metabolism in control rats and rats with streptozotocin-induced diabetes. Studies have revealed that tangeretin modulates the activity of liver enzymes due to increased insulin secretion and reduces blood glucose levels in rats with streptozotocininduced diabetes due to its antioxidant potential. ${ }^{24}$

Comparative analysis of the inhibitory activities of the purified sample $\mathrm{K}-10$ and acarbose as a reference standard showed almost the same low $\mathrm{IC}_{50}$ values of $4.82 \mathrm{mg} / \mathrm{mL}$ and $4.74 \mathrm{mg} /$ $\mathrm{mL}$, respectively, compared to $\mathrm{IC}_{50}$ of the total methanol extract (5.53 mg/mL).

The results obtained indicate that the inhibitory activity of the purified fraction, $\mathrm{K}-10$, is comparable to that of the reference drug (acarbose), and indeed contains bioactive compounds with potential inhibitory activity against $\alpha$-amylase (Figure 3 ).

\section{CONCLUSION}

Natural bioactive compounds can inhibit $\alpha$-amylase, which are the best and most useful substances to lower the blood

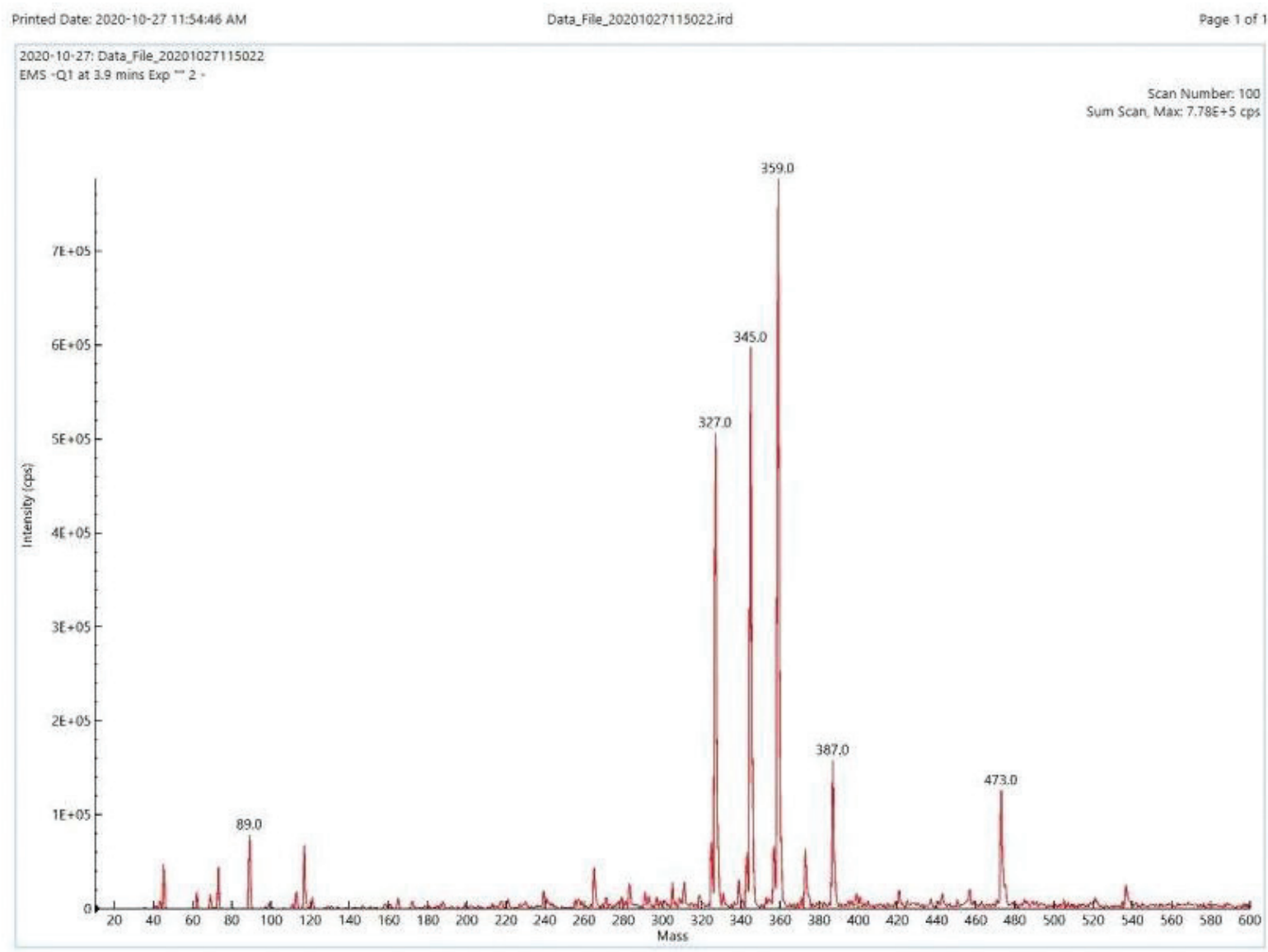

Figure 2. Mass spectral analysis of the fraction K-10 


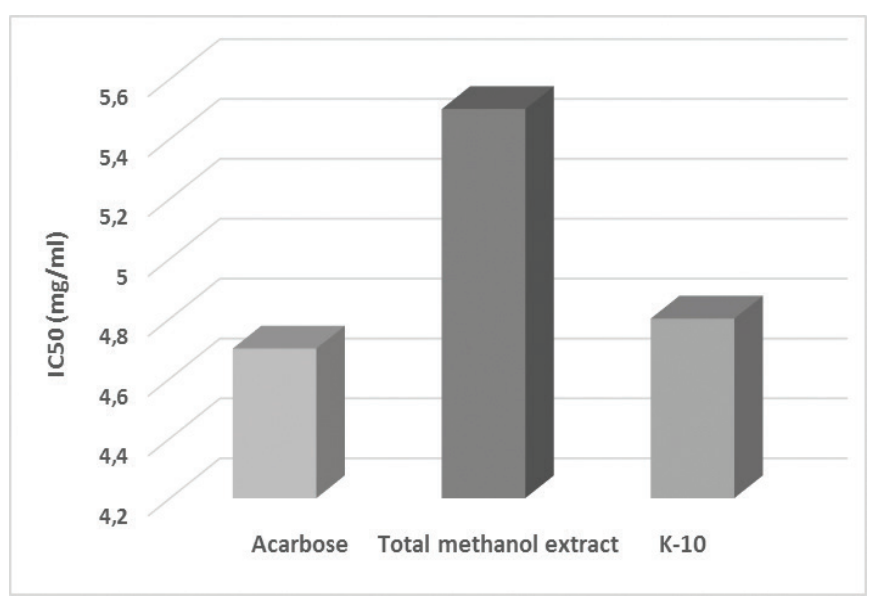

Figure 3. $\quad \mathrm{IC}_{50}$ (in $\mu \mathrm{g} / \mathrm{mL}$ ) of total methanol extract and $\mathrm{K}-10$ fraction compared with acarbose

sugar. Inhibition of $\alpha$-amylase is a successful manner in the prevention and therapy of diabetes. Therefore, the search for new sources of bioactive compounds, in particular, endophytic fungi, is an alternative way for developing new technologies for the production of microbial amylase inhibitors.

The presented studies show that the A. egypticus-HT166S endophyte from $H$. tuberosus produces PMF with high inhibitory activity against pancreatic $\alpha$-amylase, comparable to the activity of the commercial drug, acarbose. However, to establish the structure of inhibitory PMF, it is necessary to conduct further studies using analysis - infrared and nuclear magnetic resonance spectroscopy.

Based on the data obtained, it can be concluded that the endophytic fungus $A$. egypticus-HT166S can be considered a new source of pancreatic amylase inhibitors for developing hypoglycemic drugs.

\section{Ethics}

\section{Ethics Committee Approval: Not necessary.}

Informed Consent: Not necessary.

Peer-review: Externally peer-reviewed.

\section{Authorship Contributions}

Surgical and Medical Practices: I.M., G.R., Concept: S.N., Design: S.N., Data Collection or Processing: D.R., Analysis or Interpretation: T.G., Literature Search: D.R., Writing: D.R.

Conflict of Interest: No conflict of interest was declared by the authors.

Financial Disclosure: The authors declared that this study received no financial support.

\section{REFERENCES}

1. Available from: https://www.biocodexmicrobiotainstitute.com/ru/ pitanie-i-obmen-veschestv/sakharnyy-diabet-2-tipa

2. Sales PM, Souza PM, Simeoni LA, Silveira D. $\alpha$-Amylase inhibitors: a review of raw material and isolated compounds from plant source. $J$ Pharm Pharm Sci. 2012;15:141-183.
3. Dhankhar S, Dhankhar S, Yadav JP. Investigations towards new antidiabetic drugs from fungal endophytes associated with Salvadora oleoides Decne. Med Chem. 2013;9:624-632.

4. Funke I, Melzing MF. Traditionally used plants in diabetes therapy - phytotherapeutics as inhibitors of $\alpha$-amylase activity. Rev Bras Farmacogn. 2006;16:1-5.

5. Kumar S, Kumar V, Rana M, Kumar D. Enzyme inhibitors from plants: an alternate approach to treat diabetes. Phcog Comm. 2012;2:18-33.

6. Van de Laar FA, Lucassen PL, Akkermans RP, Van de Lisdonk EH, Rutten GE, Van Weel C. Alpha-glucosidase inhibitors for type 2 diabetes mellitus. Cochrane Database Syst Rev. 2005;2005:CD003639.

7. Mentreddy SR. Medicinal plant species with potential antidiabetic properties. J Sci Food Agric. 2007;87:743-750.

8. Sahani K, Thakur D, Hemalatha KPJ, Ganguly A. Antiglycemic activity of endophytic fungi from selected medicinal plants by alpha-amylase inhibition method. IJSR. 2017;6:2203-2206.

9. Fujisawa $T$, Ikegami H, Inoue K, Kawabata $Y$, Ogihara T. Effect of two alpha-glucosidase inhibitors, voglibose and acarbose, on postprandial hyperglycemia correlates with subjective abdominal symptoms. Metabolism. 2005;54:387-390.

10. Perez Gutierrez RM. Antidiabetic andantioxidant properties, and $\alpha$-amylase and $\alpha$-glucosidase inhibition effects of triterpene saponins from Piper auritum. Food Sci Biotechnol. 2016;25:229-239.

11. Kumala S, Aprilia NV, Simanjuntak P. Identification and characterization of potent antimicrobial secondary metabolite generated from endophytic fungi isolated from Jamblang plant (Eugenia cumini L.). Asian J Pharm Clin Res. 2017;10:283-286.

12. Govindappa M, Thanuja V, Tejashree S, Soukhya CA, Barge S, Manojkumar A, Ravishankar Rai V. In vitro and in silico antioxidant, anti-diabetic, anti-hiv and antialzheimer activity of endophytic fungi, Cladosporium uredinicola phytochemicals. IJPPE. 2019;13:13-34.

13. Abdulmyanova LI, Fayzieva FK, Ruzieva DM, Rasulova GA, Sattarova RS, Gulyamova TG. Bioactivity of fungal endophytes associating with Allium plants growing in Uzbekistan. Int J Curr Microbiol Appl Sci. 2016;5:769778.

14. Ruzieva D, Hasanov H, Abdulmyanova L, Rasulova G, Sattarova RS, Gulyamova TG. The effect of the extracts of endophytic fungi on pancreatic $\alpha$-amylase activity. J Food Eng. 2017;7:514-519.

15. Ruzieva D, Gulyamova T, Nasmetova S, Abdulmyanova L, Mukhammedov L, Mukhammedov I. Identification of secondary metabolites of the endophytic fungus Aspergillus egypticus-HT166S inhibiting the activity of pancreatic $\alpha$-amylase. Plant Cell Biotechnol Mol Biol. 2020;21:101-108.

16. Picot CM, Subratty AH, Mahomoodally MF. Inhibitory potential of five traditionally used native antidiabetic medicinal plants on $\alpha$-amylase, $\alpha$ -glucosidase, glucose entrapment, and amylolysis kinetics in vitro. Adv Pharmacol Sci. 2014;2014:1-7.

17. Murado MA, González MP, Vázquez JA. Dose-response relationships: an overview, a generative model and its application to the verification of descriptive models. Enzyme Microb Technol. 2002;31:439-455.

18. Prabhavathi RM, Prasad MP, Jayaramu M. Studies on qualitative and quantitative phytochemical analysis of Cissus quadrangularis. Adv Appl Sci Res. 2016;7:11-17.

19. Proença C, Freitas M, Ribeiro D, Tomé SM, Oliveira EFT, Viegas MF, Araújo AN, Ramos MJ, Silva AMS, Fernandes PA, Fernandes E. Evaluation of a flavonoids library for inhibition of pancreatic $\alpha$-amylase 
towards a structure-activity relationship. J Enzyme Inhib Med Chem. 2019;34:577-588

20. Zhang J, Jianqiu L, Zhang Q, Dai L, Liu Y, Tu P, Qiao Y. Simultaneous screening and identifying four categories of particular flavonoids in the leaves of Murraya exotica L. by HPLC-DAD-ESI-MS-MS. J Chromatogr Sci. 2014;52:103-114

21. Li RW, Theriault AG, Au K, Douglas TD, Casaschi A, Kurowska EM, Mukherjee R. Citrus polymethoxylated flavones improve lipid and glucose homeostasis and modulate adipocytokines in fructose-induced insulin resistant hamsters. Life Sci. 2006;79:365-373.
22. Gandhi GR, Vasconcelos ABS, Wu DT, Li HB, Antony PJ, Li H, Geng F, Gurgel $R Q$, Narain N, Gan RY. Citrus flavonoids as promising phytochemicals targeting diabetes and related complications: a systematic review of in vitro and in vivo studies. Nutrients. 2020;12:2907.

23. Nguyen-Ngo C, Salomon C, Quak S, Lai A, Willcox JC, Lappas M. Nobiletin exerts anti-diabetic and anti-inflammatory effects in an in vitro human model and in vivo murine model of gestational diabetes. Clin Sci (Lond). 2020;134:571-592.

24. Sundaram R, Shanthi P, Sachdanandam P. Effect of tangeretin, a polymethoxylated flavone on glucose metabolism in streptozotocininduced diabetic rats. Phytomedicine. 2014;21:793-799. 